\title{
LXXV. On the ionization produced by $\alpha$ rays
}

\section{Howard L. Bronson Ph.D.}

To cite this article: Howard L. Bronson Ph.D. (1906) LXXV. On the ionization produced by $\alpha$ rays, Philosophical Magazine Series 6, 11:66, 806-812, DOI: $10.1080 / 14786440609463501$

To link to this article: http://dx.doi.org/10.1080/14786440609463501

曲 Published online: 16 Apr 2009.

Submit your article to this journal $₫$

Џ Article views: 2

Q View related articles $₫$

4 Citing articles: 1 View citing articles 준 


\section{[ 806 ]}

\section{On the Ionization produced by a Rays. By Howard L. Bronson, Ph.D.**}

TWHE following paper contains an account of the investi1 gation of two entirely distinct, but closely related problems. The first is an investigation to determine how the ionization produced by an $\alpha$ particle varies near the end of its path. The second is an investigation to prove definitely whether or not radium B emits a particles which are able to ionize the air for even a short distance.

Investigations by Bragg and Kleeman (Phil. Mag. Dec. 1904) and by McClung (Phil. Mag. Jan. 1906) on the ionization due to the rays from radium $\mathrm{C}$, have shown that the ionization per $\mathrm{cm}$. increases gradually with the distance from the source for about $6 \mathrm{cms}$. and then decreases exceedingly rapidly, falling to zero or very nearly to zero at $7 \mathrm{cms}$. Rutherford (Phil. Mag. July 1905, Jan. 1906, and April 1906) examined the photographic action of the $\alpha$ rays from radium $\mathrm{C}$, but was unable to get any evidence of such action through more than about $7 \mathrm{cms}$. of air. His calculations, based on the amount of magnetic deflexion of the a particles which had passed through matter equivalent in absorbing power to nearly $7 \mathrm{cms}$. of air, show that the a particles still possessed about 40 per cent. of their initial velocity, while the photographic action was relatively very feeble.

Now Townsend (Phil. Mag. Nov. 1903) has shown that a positive ion of mass comparable with that of the a particle is able to produce fresh ions by collision, when its velocity is undoubtedly very much smaller than that of the $x$ particle at the time when it apparently loses its ionizing power. In Townsend's experiments, however, the positive ion was a very inefficient ionizer compared with the a particle, for it produced fresh ions at only a small fraction of the total number of collisions with the gas molecules, while Rutherford ('Radioactivity,' p. 434) has shown that it is probable that the $a$ particle at its maximum efficiency produces an ion at practically every collision.

It would thus appear probable either that the velocity of the $\alpha$ particle decreases very rapidly when it falls below about 40 per cent. of its maximum, or that its efficiency as an ionizer falls off very rapidly without a corresponding falling off in the velocity. In the latter case, we might expect to find a small ionizing action extending for a considerable distance beyond $7 \mathrm{cms}$. An investigation of this point therefore seemed desirable.

* Communicated by Prof. E. Rutherford, F.R.S. 
The method of Bragg and Kleeman, which was so well adapted to the determination of the ionization per $\mathrm{cm}$. along the early portion of the path of the a particle, did not seem to be equally well adapted to the present problem. In their method, it is necessary to use a pencil of rays of small angle and a very narrow testing-vessel; conditions which it is practically impossible to employ in the measurement of a very small ionizing action, such as it was thought the $a$ particle might still produce after passing through 7 cms. of air.

Fig. 1.

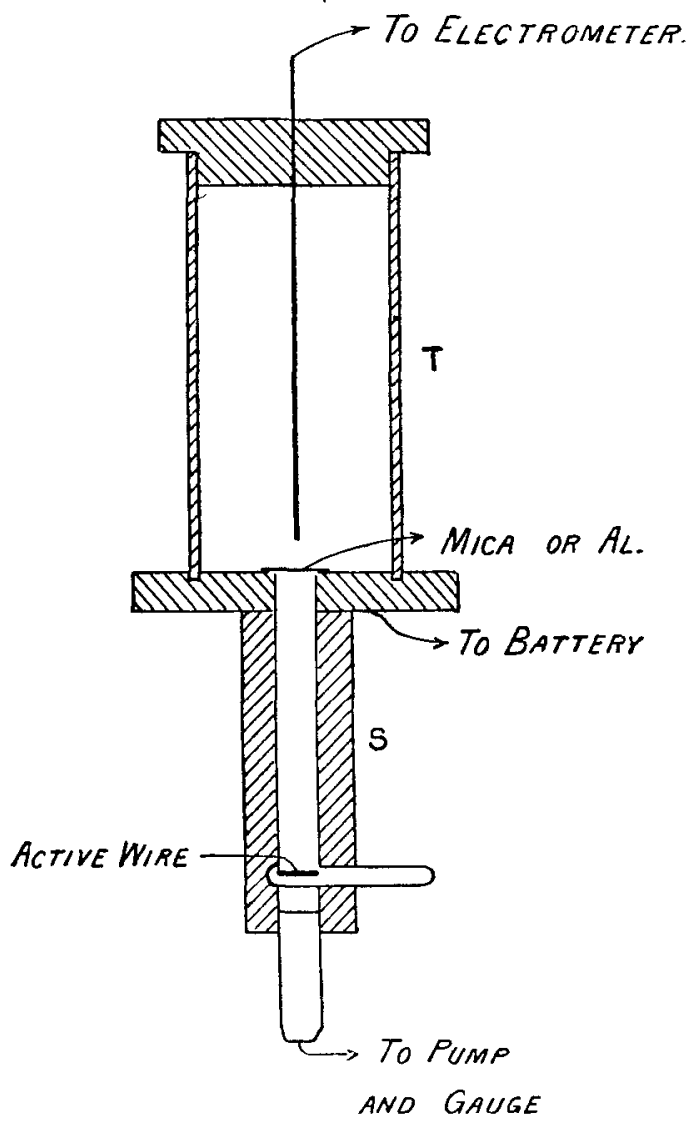

The method therefore adopted in the present experiment was always to measure the total ionization caused by the a particle beyond a certain distance from the source. Fig. 1 shows the arrangement of the testing-vessel employed. T, the testing-vessel proper, is a brass cylinder of sufficient 
diameter and height to include the entire cone of rays under all circumstances. The central electrode was insulated by an ebonite cork and connected to an electrometer. Below the testing-vessel there was another brass cylinder, $\mathbf{S}$, having an internal diameter of $0.6 \mathrm{~cm}$. The opening between this and the testing-vessel was closed with mica or aluminium. The active wire could be easily placed in position through an opening in the side. The distance between the mica and active wire was $4.7 \mathrm{cms}$., which made the maximum angle of the cone of rays less than $8^{\circ}$. A water-pump was used to exhaust the chamber $\mathbf{S}$. The pressure was easily measured on a gauge, and the equivalent thickness of air at $76 \mathrm{cms}$. pressure was calculated. This method of varying the amount of material through which the $a$ particle bad to pass before entering the testing-vessel, was found to be very simple and exceedingly satisfactory. In this way it was possible to take an entire set of observations without disturbing the apparatus or even going near it. In order to be able to measure very small amounts of ionization due to the $a$ rays, the $\beta$ rays were bent away by placing the cylinder $S$ between the poles of a strong electromagnet. The ionization was measured by an electrometer using the constant deflexion method, and the values obtained were corrected for the decay of radium $\mathrm{C}$.

The mica was covered with a leaf of Dutch metal to prevent electrostatic action, and the thickness of the two was found to correspond to $2.22 \mathrm{cms}$. of air at a pressure of $76 \mathrm{cms}$. As this and the $4.7 \mathrm{cms}$. of air between the mica and the active wire was not sufficient to entirely absorb the a particles, the lower part of the curve, fig. 2 , was obtained with an additional covering of aluminium equivalent to $1.22 \mathrm{cms}$. of air.

The results of this experiment are shown in the curve of fig. 2. The abscissæ represent the total number of cms. of air, or its equivalent, through which the $a$ particles have passed before entering the testing-vessel $\mathrm{T}$. The ordinates represent the ionization produced, expressed as percentages of the total ionization caused by the $a$ particles over their entire path. The percentages are not exact, for the maximum value was obtained by extrapolation from the curve. The conclusions to be drawn from this curve are substantially the same as those of Bragg and Kleeman, and of McClung. The number of ions per $\mathrm{cm}$. produced by the a particle increases gradually over the first $6.4 \mathrm{cms}$. of its path and then decreases very rapidly, falling to less than 0.5 per cent. of the total at $7 \cdot 1 \mathrm{cms}$.

Two experimental conditions might account for the apparent rapid decrease in the ionization per $\mathrm{cm}$. of the $\alpha$ 
particle towards the end of its path. In the first place, the cone of rays had a sensible angle, but calculations showed that this could not account for more than one-tenth of the observed effect. In the second place, inequalities in the

Fig. 2.

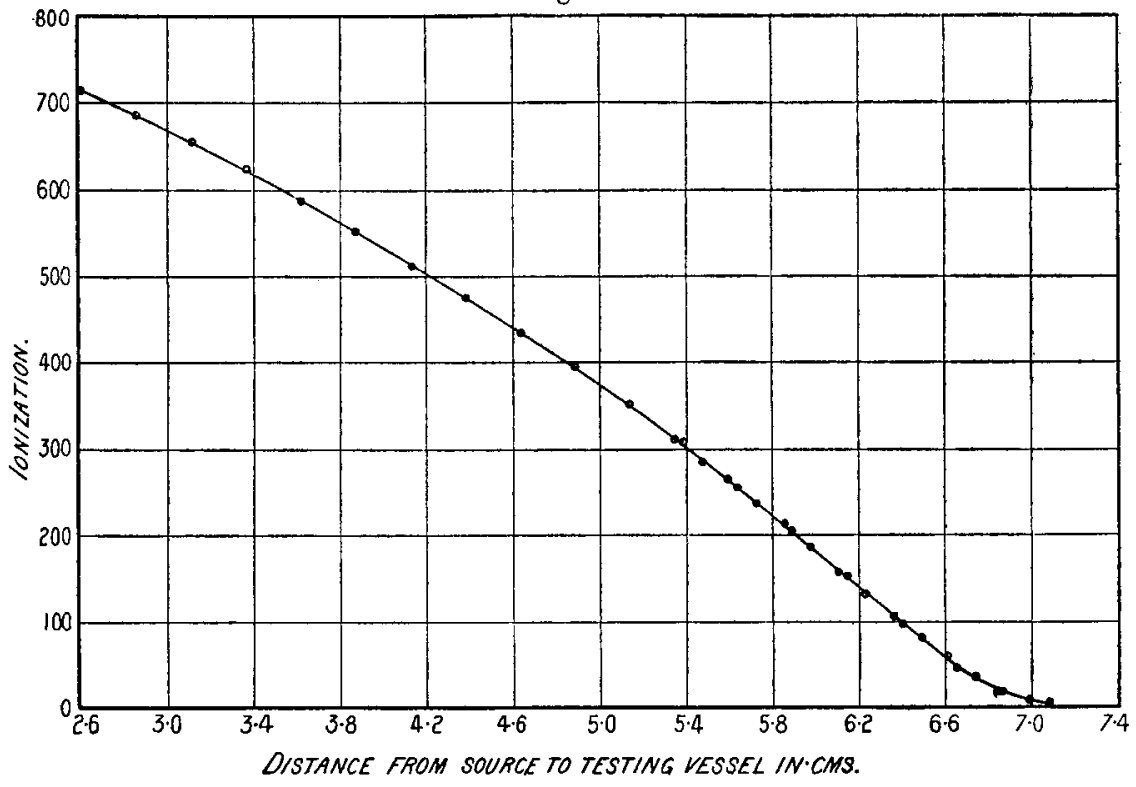

thickness of the mica and aluminium used might produce the same effect. In order to test this point, two samples of mica and four of aluminium were selected with care, and used successively with almost identical results. It therefore seems certain that the ionization per $\mathrm{cm}$., produced by the $\alpha$ particle in air, decreases very rapidly between $6.4 \mathrm{cms}$. and $7 \cdot 1 \mathrm{cms}$. from its source.

In order to see whether there was any evidence that the $\alpha$ particle continued to produce ions beyond about $7 \cdot 5 \mathrm{j} \mathrm{cms}$., a very strongly excited wire was used, and the magnitude of the ionization due to the different causes was measured. The maximum ionization per $\mathrm{cm}$. due to the $a$ rays corresponded to about 600 divisions deflexion of the electrometer, and that due to the $\beta$ rays corresponded to about 8 divisions. When the $\beta$ rays were bent away by a magnetic field and the effect due to the $\gamma$ rays and natural leak subtracted, the remaining ionization per $\mathrm{cm}$. did not correspond to more than 0.4 division. It therefore seems safe to conclude that the ionizing power of the $\alpha$ particle has certainly fallen below Phil. Maq. S. 6. Vol. 11. No. 66. June 1906. $3 \mathrm{G}$ 
0.07 per cent. of its maximum value. In fact there is no evidence that any such ionization exists.

It thus appears likely that the a particle loses its energy very rapidly near the end of its path by collision with the gas molecules, and is completely absorbed by a thickness of air of $7 \cdot 2 \mathrm{cms}$.

Does Radium $B$ emit a Rays?

Schmidt (Physikalische Zeitschrift, Jan. 1906) has shown that radium $B$ gives out $\beta$ rays of small penetrating power. This suggests the possibility that radium $B$ may also give out $\alpha$ rays of small velocity. A slight irregularity, obtained by the writer, in the decay curves of the excited activity from radium also seemed to indicate that there might be a small amount of $\alpha$-ray ionization from radium $B$. This would mean that the velocity of these $\alpha$ particles was sufficient to ionize possibly two or three millimetres of air, in which case the effect would be so small that generally it would be entirely masked by the ionization from radium C. Since radium $B$ continuously produces radium $\mathrm{C}$, the possibility of getting the former entirely separated from the latter, and keeping it separated long enough to test the above point, seemed

Fig. 3.

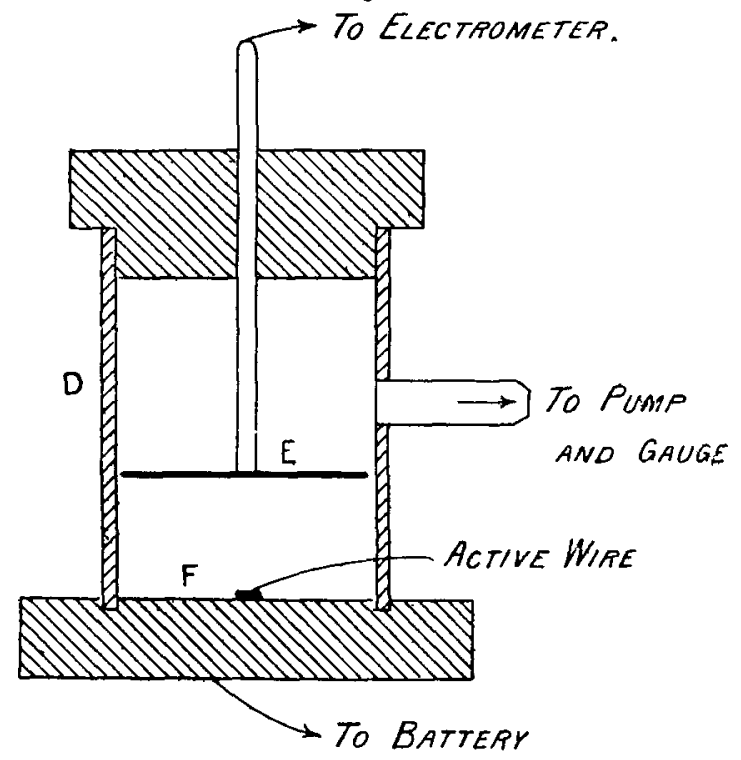

hopeless. Therefore the following method, suggested by Professor Rutherford, was adopted.

The arrangement of the testing-vessel is shown in fig. 3. 
The measurements of pressure and ionization were taken exactly as in the previous experiment. Four separate experiments were performed with testing-vessels of different dimensions. The four diameters used for the tube $\mathrm{D}$ were $9 \cdot 6 \mathrm{cms} ., 6 \cdot 2 \mathrm{cms} ., 2 \cdot 0 \mathrm{cms}$. and $0.6 \mathrm{~cm}$. ; and in each case the distance between $\mathrm{E}$ and $\mathrm{F}$ was equal to one-half the diameter of the tube.

Now let us consider the case where the diameter of the tube $\mathrm{D}$ is $2 \mathrm{cms}$. In this case the average path of the $\alpha$ particles from radium $\mathrm{C}$ will be about $1 \mathrm{~cm}$. If the ionization is entirely due to them, we should expect it to be proportional to the pressure of the air. Now let us suppose that radium $\mathrm{B}$ also emits the same number of a particles as radium (', and that each one produces the same number of ions per $\mathrm{cm}$., but that their range of ionization is only $0.2 \mathrm{~cm}$. If now the pressure is diminished, the range of the $\alpha$ particles from radium $B$ will increase, and the total ionization produced by them will remain the same, until the pressure has fallen to one-fifth of an atmosphere, when the path of these $\alpha$ particles will extend to the sides of the testing-vessel.

The following table gives the theoretical relation between pressure and ionization calculated on the above assumptions.

$\begin{array}{cccc}\begin{array}{c}\text { Pressure in } \\ \begin{array}{c}\text { tmospheres. } \\ \mathbf{1} \cdot 0\end{array}\end{array} & \begin{array}{c}\text { Ionization } \\ \text { due to Radium }\end{array} & \begin{array}{c}\text { Ionization } \\ \text { due to Radium B. }\end{array} & \text { Total. } \\ 0.9 & 10 & 2 & 12 \\ 0.8 & 9 & 2 & 11 \\ 0.7 & 8 & 2 & 10 \\ 0 \cdot 6 & 7 & 2 & 9 \\ 0.5 & 6 & 2 & 8 \\ 0.4 & 5 & 2 & 7 \\ 0.3 & 4 & 2 & 6 \\ 0.2 & 3 & 2 & 5 \\ & 2 & 2 & 4\end{array}$

Thus after the pressure has been reduced to 0.2 of an atmosphere, the ionization should be nearly twice as large as though radium $B$ emitted no a particles.

Curve 1 (fig. 4, p. 812) was obtained using the smallest of the four testing-vessels. Curve 2 was calculated on the assumption that the ionizing path of the $\alpha$ particles from radium $B$ is $0.03 \mathrm{~cm}$. There is no evidence from the experimental curve that the ionization is not exactly proportional to the pressure. Exactly similar results were obtained with the other testing-vessels, and the largest one would have detected a rays from radium $B$ having a range of ionization as long as 2 cms. It therefore seems safe to conclude that radium B 3 G 2 
does not give off a particles or, at any rate, none of sufficient velocity to ionize air.

Fig. 4.

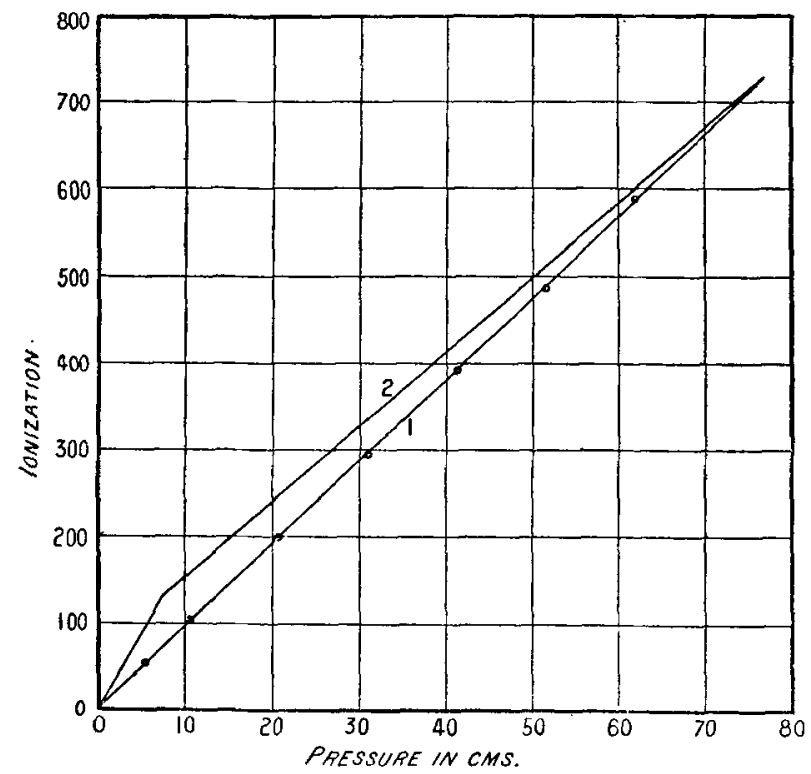

In conclusion I desire to express my indebtedness to Professor Rutherford for suggesting and kindly supervising this investigation.

Macdonald Physics Building, MeGill University, Montreal, April 7, 1906.

LXXVI. Secondary Röntgen Radiation. By CharLes G. BARKLA, D.Sc. (Liverpool), M.Sc. (Victoria), B.A. (King's College, Cambridge); Lecturer in Advanced Electricity, University of Liverpool *.

\section{Introduction.}

QINCE the discovery by Röntgen of secondary radiation $O$ from substances exposed to X-rays, the subject has been investigated by a number of experimenters, including Perrin, Townsend, Dorn, Curie, Sagnac, Langevin, and Bumstead $\uparrow$.

* Communicated by the Physical Society : read February 23, 1906.

† Perrin, Annales de Chimie et de I'hysique, [7] xi. p. 496 (1897). Townsend, Proc. Camb. Phil. Soc. x. p. 217 (1899). Dorn, Abhand. d. naturf. (Y)es. zu Halle, xxii. p. 39 (1000). Sagnac, Annales de Chimie et de Physique, [7] xxii. p. 493 (1901). Curio \& Sagnac, Journal de Physique, [4] i. p. 13 (1902). Langevin, Recherches sur les gaz ionisés. Bumstead, Phil. Mag. xi. pp. 292-317, Feb. 1906. 